\title{
Pattern of Acute Poisoning among Patients Admitted to Tanta Poison Control Center during 2012
}

\author{
Mona Mohamed Abo El- Noor'1
}

${ }^{1}$ Department of Forensic Medicine and Toxicology, Faculty of Medicine, Tanta University, Tanta, Egypt.

\begin{abstract}
Background: Acute poisoning remains a major public health problem and represents a frequent cause of admission in emergency units, especially in developing countries. Many studies must be focused on the different patterns of acute poisoning in patients admitted to poison control centers. So, the aim of this study is to characterize the poisoning cases admitted to poison control center, Tanta University Emergency Hospital, Egypt.

Study design: All admitted acutely poisoned patients from January to December 2012 were evaluated retrospectively. Data of socio-demographic characteristics, time of admission, circumstances of poisoning, agents, route of exposure and mortality rate were collected from medical records of the hospital. During this period, 1104 patients were admitted.

Results: Of the admitted patients, $57.1 \%$ were females and $42.9 \%$ were males. The majority $(31.2 \%)$ of cases were in the age group between 1-10 years. Most poisonings were accidental (55.2\%) while suicidal attempts were $44.8 \%$. Females were $76.2 \%$ of all suicidal poisoning while males were $58.5 \%$ of all accidental poisoning. The most important agents used were therapeutic drugs $(32.3 \%)$ especially sedatives and hypnotics (12.6\%) followed by analgesics $(9.24 \%)$ and CVS drugs $(8.96 \%)$. Pesticides were the second common agents used $(28.6 \%)$ of which organophosphates were the commonest (67.7\%). Mortality rate was $0.5 \%$ which was due to suicidal attempts by pesticides.

Conclusion: The study concluded that high rate of acute poisoning was between patients of age group between 1-10 years. Females were of high suicidal attempts than males, while males were predominant in accidental poisoning. The most commonly substances included are drugs and pesticides. Prevention strategies should be directed towards limiting access to the implicated substances involved in both accidental and suicidal poisoning.
\end{abstract}

\section{Introduction}

A cute poisoning is exposure to a poison on one occasion or during a short period of time. Symptoms develop in close relation to the exposure. Poison can be defined as any substance that causes a harmful effect when administered, either by accident or design, to a living organism. Poison is a quantitative concept, almost any substance can be harmful at some doses but, at the same time, being without harmful effect at some lower dose (Hodgson, 2004).

Acute poisoning is still an important public health problem and represents a frequent cause of admission in emergency units, especially in developing countries (Sahin et al., 2011).

Annually, more than 2 million cases of poison exposure are reported to poison centers in the United States (Watson et al., 2004). It is estimated that some forms of poisons are directly or indirectly responsible for more than 1 million illnesses worldwide annually (Pillay, 2004). The exact number of incidences can be higher, because most cases of the poisoning actually go unreported.

According to the 2004 World Health Report, it is estimated that 350,000 people died from unintentional poisoning worldwide in 2002; half of them in Southeast Asia and Western Pacific region (Yang, 2010).

Acute poisoning may be due to drugs, chemical substances, animal venom or plant toxins. The problem is getting worse with time as newer drugs and chemicals are developing. Poisoning cases are increasing day-by-day due to changes in the life style and social behavior. The causes of poisoning can be civilian, industrial, accidental, and deliberate or suicidal (Shadnia et al., 2007).

The mortality rate due to poisoning is $3-5 \%$ (Agarwal and Gupta 1984; Buch et al.,1991 and Mutlu et al.,2010). The pattern and main risks of acute poisoning change with time according to age, and they differ from country to country. Thus epidemiological 
surveillance specific for each country is necessary to determine the extent and characteristics of the problem, according to which related preventive measures can be taken (Sahin et al.,2011).

Tanta poison control center is the only available, well-equipped and qualified center in ElGharbia governorate area. It is located in the center of delta Egypt. It provides valuable, informative advice, overdose diagnosis, best possible health care and management of acute poisoning cases to general public living in this area. It serves large population and treats patients referred by other district hospitals. Also, it provides advice and training to medical hospital personnel (i.e., physicians, pharmacists and nurses) and non-medical callers from all over this area.

So, the objective of this study is to assess the patterns of acute poisoning among patients admitted to Tanta poison control center in the year 2012 .

\section{Patients and methods}

\section{Patients}

This retrospective study was conducted on acute poisoned patients admitted to Poison Control Center, Tanta University Emergency Hospital, Egypt. Data were collected from records and documentation forms of all admitted acutely poisoned patients during the study period from January to December 2012.

Patients were classified according to age into the following groups:

$$
\begin{aligned}
& \text { - Group 1: 1- } 10 \\
& \text { years } \\
& \text { - Group 2: 11-20 } \\
& \text { years } \\
& \text { - Group 3: 21-30 } \\
& \text { years } \\
& \text { - Group 4: 31-40 } \\
& \text { years } \\
& \text { - Group 5: 41-50 } \\
& \text { years } \\
& \text { - Group 6: 51-60 } \\
& \text { years } \\
& \text { - Group 7: more than } \\
& 60 \text { years }
\end{aligned}
$$

\section{Methods}

Toxicological sheets were reviewed for the following items:

- Personal history: age, sex, residence, admission date and circumstances of poisoning .

- Toxicological history: identification of substances (poisons and/or drugs) used and its route of administration.

\section{- Past history: \\ psychiatric illness and drug abuse.}

Accidents included external causes of poisoning and self inflected accidents (e.g. taking the wrong medication where the agent was not used for self-harm or intoxication purposes. Poisonings due to substance abuse, such as heroin, tramadol, hashish and ethanol taken for intoxication purposes, were defined as accidental overdoses with substances of abuse. Data of reports were transferred into a basic data sheet and evaluated statistically.

Ethics approval for the study was obtained from the Research Ethics and Publications Committee of the Faculty of Medicine, Tanta University, Egypt. Approval of the head of the Poison Control Center was taken. Confidentiality of records was maintained by keeping the records anonymous.

\section{Statistical analysis}

Data were entered into SPSS statistical program version 17, Chicago IL. Descriptive statistics were used to describe the sample and p-values less than or equal to 0.05 were considered to be statistically significant. The statistical test for comparison used was the Chi-square test.

\section{Results}

This study included 1104 patients admitted to poison control center, Tanta University Emergency Hospital, Egypt in the year 2012. The age of the patients included in this study ranged between 1 to 75 years.

In this study, acute poisoning was prevalent in the age group between 1-10 years (344 patients, $31.2 \%$ ), followed by age group between $11-20$ years (303 patients, 27.4\%) while the least cases were among age group of more than 60 years (10 patients, $0.9 \%)$ (Table 1).

Acutely poisoned females were 630 (57.1\%) of total number of patients while male patients with toxic exposure were 474 (42.9\%). (Table1, Figure1).

As regard the circumstances of poisoning, this study revealed that acute poisoning was either accidental or attempted suicide. Accidental poisoning occurred in $609(55.2 \%)$ while suicidal poisoning occurred in 495(44.8\%) (Table1, Figure2).

Females $(n=377,76.2 \%)$ predominated males $(n=118,23.8 \%)$ in suicidal attempts while the reverse occurred in accidental poisoning as males were 356 $(58.5 \%)$ and females were 253 (41.5\%) (Table 2).

The distribution of different age groups, gender according to circumstances of poisoning was done. This revealed that suicidal poisoning among females in the age group between 11- 20 years was the commonest $(n=206,86.2 \%$ of this age group) followed by age group between $21-30$ years $(n=136,69 \%$ of this age group), while the age group of more than 60 years was the least ( $n=1,100 \%$ of this age group). Suicidal attempts in male patients were more prevalent in the age group between 21 - 30 years $(n=61,31 \%$ of this age group). As regard accidental poisoning, the commonest cases were among males in the age group between 1-10 
years $(58.2 \%)$ and females were $41.8 \%$ of this age group. While the least was among patients more than 60 years, males and females $(77.8 \%$ and $22.2 \%$ of this age group respectively) (Table 3 )

Table (1) revealed that patients with a history of psychological disturbances constituted 12 of all patients $(1.1 \%)$, while patients with a history of drug abuse were 23 of all cases $(2.1 \%)$.

The current study revealed that acute poisoning was more prevalent in rural areas (598, $54.2 \%$ ) than in urban areas $(506,45.8 \%$ ) (Table1, Figure 3).

More than $80 \%$ of the studied patients $(n=$ 908) were exposed through oral route compared to 87 $(7.9 \%), 82(7.4 \%), 12(1.1 \%), 8(0.7 \%)$ and $7(0.6 \%)$ patients through inhalation, bite, inhalation plus dermal, injection and dermal respectively. Only one case of suicidal attempts was through injection $(0.2 \%)$ while the rest of cases was by oral route $(n=494$, $99.8 \%$ while in accidental poisonings all different routes were included (Table 4).

The common agents involved in the poisoning were drugs $(n=357,32.3 \%)$ followed by pesticides $(n=316,28.6 \%)$, while the least agents used were hashish $(n=4,0.4 \%)$ and heroin $(n=2,0.2 \%)$. It was observed that therapeutic drugs are the predominant among agents used for suicidal attempts $(n=247,49.9 \%$ of all suicides), while pesticides are the most prevalent among accidental poisoned patients $(n=125,20.7 \%$ of all accidental poisonings). There were some agents involved absolutely accidentally as bites $(\mathrm{n}=82$, $13.3 \%)$, food poisoning $(n=27,4.4 \%)$, chlorine gas $(n=$ $24,3.9 \%)$, carbon monoxide $(n=16,2.6 \%)$, hashish $(n=$ $4,0.7 \%)$ and heroin $(n=2,0.3 \%)$ of all accidental poisonings (table 5).

In the current study, there was a significant difference between accidental and suicidal poisoning with benzene $(p=0.005) .1 .4 \%$ of patients were poisoned with miscellaneous substances such as cosmetics, akim's body oil, naphthalene and various stings. A significant percentage $(5 \%)$ of poisoned patients both accidentally and suicidal was through use of a mixture of unknown substances (Table 5).

Among the various types of drugs used by patients in this study, sedatives and hypnotics were the commonest used $(n=45,12.6 \%)$, followed by analgesics $(n=33,9.24 \%)$ then CVS drugs $(n=32$, $8.96 \%$ ) (table 6).

The most common drugs used for suicidal attempts were sedatives and hypnotics ( $\mathrm{n}=$ $33,11,45 \%)$ followed by analgesics and theophylline ( each of $n=27,9.37 \%$ ), while the most drugs accidentally used were sedatives and hypnotics $(n=12$, $17.39 \%$ ) followed by antipsychotics and CVS drugs (each of $n=8,11.59 \%$ ) (Table 6)

Among pesticides, most poisonings were caused by organophosphates $(n=214,67.7 \%)$ followed by zinc phosphide $(\mathrm{n}=54,17.1 \%)$ then carbamates $(\mathrm{n}=27,8.5 \%)$ and lastly, aluminium phosphide $(\mathrm{n}=11$, $3.5 \%)$ and pyrethroids $(\mathrm{n}=10,3.2 \%)$ (table 7$)$.

As regard gender and its correlation to the type of poisoning, it was found that the most used for males was pesticides $(n=134,42.4 \%)$, while therapeutic drugs were the most used type for females $(\mathrm{n}=253,70.9 \%)($ table 8$)$

Pesticides were more common agents involved in rural areas than urban areas $(60.8 \%$ and $39.2 \%$ respectively), while therapeutic drugs were more common agents involved in urban than rural areas (50.7\% and $49.3 \%$ respectively) (Table 9 ).

Finally, mortality rate in this study was $0.5 \%$ of all cases. All the five cases (2males and 3 females) were suicidal by pesticides.

Table (1): Percentage of general characteristics of the studied patients (Number=1104).

\begin{tabular}{|l|l|c|c|}
\hline \multirow{4}{*}{ Sex } & & $\mathbf{N}$ & $\mathbf{\%}$ \\
\hline \multirow{5}{*}{ Age } & Male & 474 & 42.9 \\
\cline { 2 - 4 } & Female & 630 & 57.1 \\
\hline \multirow{5}{*}{ Residence } & $1-10$ years & 344 & 31.2 \\
\cline { 2 - 4 } & $11-20$ years & 303 & 27.4 \\
\cline { 2 - 4 } & $21-30$ years & 285 & 25.8 \\
\cline { 2 - 4 } & $31-40$ years & 84 & 7.6 \\
\cline { 2 - 4 } & $41-50$ years & 41 & 3.7 \\
\cline { 2 - 4 } & $51-60$ years & 37 & 3.4 \\
\cline { 2 - 4 } & $>60$ years & 10 & .9 \\
\hline Psychological Disturbance & Rural & 598 & 54.2 \\
\cline { 2 - 4 } & Urban & 506 & 45.8 \\
\hline & Yes & 12 & 1.1 \\
\cline { 2 - 4 } & No & 1092 & 98.9 \\
\hline Drug Abuse & Yes & 23 & 2.1 \\
\cline { 2 - 4 } & No & 1081 & 97.9 \\
\hline Manner Of Toxicity & Suicidal & 495 & 44.8 \\
\cline { 2 - 4 } & Accidental & 609 & 55.2 \\
\hline \multirow{3}{*}{ N= number } & \multicolumn{2}{|c}{} \\
\hline
\end{tabular}

Table (2): Chi square statistical analysis of studied patients according to circumstances of poisoning gender. 


\begin{tabular}{|c|c|c|c|c|c|c|c|}
\hline \multirow{3}{*}{ Sex } & \multicolumn{4}{|c|}{ Manner of toxicity } & \multirow{2}{*}{\multicolumn{2}{|c|}{ Total }} & \multirow{3}{*}{ p. value } \\
\hline & \multicolumn{2}{|c|}{ Suicidal } & \multicolumn{2}{|c|}{ Accidental } & & & \\
\hline & $\mathbf{N}$ & $\%$ & $\mathbf{N}$ & $\%$ & $\mathbf{N}$ & $\%$ & \\
\hline Male & 118 & 23.8 & 356 & 58.5 & 474 & 42.9 & 0.001 \\
\hline Female & 377 & 76.2 & 253 & 41.5 & 630 & 57.1 & 0.001 \\
\hline Total & 495 & 100 & 609 & 100 & 1104 & 100 & - \\
\hline
\end{tabular}

Significant $p<0.05, N=$ number

Table (3): Chi square statistical analysis of studied patients according to age groups, gender and circumstances of poisoning.

\begin{tabular}{|c|c|c|c|c|c|c|c|c|}
\hline \multirow{3}{*}{ Age } & \multirow{3}{*}{ Sex } & \multicolumn{6}{|c|}{ Manner of toxicity } & \multirow{3}{*}{ p.value } \\
\hline & & \multicolumn{2}{|c|}{ Suicidal } & \multicolumn{2}{|c|}{ Accidental } & \multicolumn{2}{|c|}{ Total } & \\
\hline & & $\mathbf{N}$ & $\%$ & $\mathbf{N}$ & $\%$ & $\mathbf{N}$ & $\%$ & \\
\hline \multirow[t]{3}{*}{$1-10$ years } & Male & 4 & 57.1 & 196 & 58.2 & 200 & 58.1 & \multirow{3}{*}{0.622} \\
\hline & Female & 3 & 42.9 & 141 & 41.8 & 144 & 41.9 & \\
\hline & Total & 7 & 100 & 337 & 100 & 344 & 100 & \\
\hline \multirow[t]{3}{*}{$11-20$ years } & Male & 33 & 13.8 & 37 & 57.8 & 70 & 23.1 & \multirow{3}{*}{0.001} \\
\hline & Female & 206 & 86.2 & 27 & 42.2 & 233 & 76.9 & \\
\hline & Total & 239 & 100 & 64 & 100 & 303 & 100 & \\
\hline \multirow[t]{3}{*}{$21-30$ years } & Male & 61 & 31 & 52 & 59.1 & 113 & 39.6 & \multirow{3}{*}{0.001} \\
\hline & Female & 136 & 69 & 36 & 40.9 & 172 & 60.4 & \\
\hline & Total & 197 & 100 & 88 & 100 & 285 & 100 & \\
\hline \multirow[t]{3}{*}{$31-40$ years } & Male & 13 & 38.2 & 29 & 58 & 42 & 50 & \multirow{3}{*}{0.060} \\
\hline & Female & 21 & 61.8 & 21 & 42 & 42 & 50 & \\
\hline & Total & 34 & 100 & 50 & 100 & 84 & 100 & \\
\hline \multirow[t]{3}{*}{$41-50$ years } & Male & 5 & 38.5 & 17 & 60.7 & 22 & 53.7 & \multirow{3}{*}{0.160} \\
\hline & Female & 8 & 61.5 & 11 & 39.3 & 19 & 46.3 & \\
\hline & Total & 13 & 100 & 28 & 100 & 41 & 100 & \\
\hline \multirow[t]{3}{*}{$51-60$ years } & Male & 2 & 50 & 18 & 54.5 & 20 & 54.1 & \multirow{3}{*}{0.630} \\
\hline & Female & 2 & 50 & 15 & 45.5 & 17 & 45.9 & \\
\hline & Total & 4 & 100 & 33 & 100 & 37 & 100 & \\
\hline \multirow[t]{3}{*}{$>60$ years } & Male & 0 & 0 & 7 & 77.8 & 7 & 70 & \multirow{3}{*}{0.330} \\
\hline & Female & 1 & 100 & 2 & 22.2 & 3 & 30 & \\
\hline & Total & 1 & 100 & 9 & 100 & 10 & 100 & \\
\hline
\end{tabular}

Significant $p<0.05, N=$ number

Table (4): Chi square statistical analysis of studied patients according to circumstances of poisoning and route of exposure.

\begin{tabular}{|c|c|c|c|c|c|c|c|}
\hline \multirow{3}{*}{ Route } & \multicolumn{4}{|c|}{ Manner of toxicity } & \multirow{2}{*}{\multicolumn{2}{|c|}{ Total }} & \multirow{3}{*}{ p. value } \\
\hline & \multicolumn{2}{|c|}{ Suicidal } & \multicolumn{2}{|c|}{ Accidental } & & & \\
\hline & $\mathbf{N}$ & $\%$ & $\mathbf{N}$ & $\%$ & $\mathbf{N}$ & $\%$ & \\
\hline Oral & 494 & 99.8 & 414 & 67.9 & 908 & 82.2 & 0.006 \\
\hline Inhalation & 0 & 0 & 87 & 14.3 & 87 & 7.9 & - \\
\hline Bite & 0 & 0 & 82 & 13.5 & 82 & 7.4 & - \\
\hline Dermal+ inhalation & 0 & 0 & 12 & 1.9 & 12 & 1.1 & - \\
\hline Injection & 1 & 0.2 & 7 & 1.14 & 8 & 0.7 & 0.005 \\
\hline Dermal & 0 & 0 & 7 & 1.14 & 7 & 0.6 & - \\
\hline Total & 495 & 100 & 609 & 100 & 1104 & 100 & - \\
\hline
\end{tabular}

Significant $p<0.05, N=$ number 
Table (5): Chi square statistical analysis of studied patients according to types of poisons and circumstances of poisoning.

\begin{tabular}{|c|c|c|c|c|c|c|c|}
\hline & \multicolumn{4}{|c|}{ Manner of toxicity } & \multirow{2}{*}{\multicolumn{2}{|c|}{ Total }} & \multirow{3}{*}{ p. value } \\
\hline & \multicolumn{2}{|c|}{ Suicidal } & \multicolumn{2}{|c|}{ accidental } & & & \\
\hline & $\mathbf{N}$ & $\%$ & $\mathbf{N}$ & $\%$ & $\mathbf{N}$ & $\%$ & \\
\hline Therapeutic drugs & 247 & 49.9 & 110 & 18.1 & 357 & 32.3 & 0.030 \\
\hline Pesticides & 191 & 38.4 & 125 & 20.7 & 316 & 28.6 & 0.018 \\
\hline Corrosives & 5 & 1 & 96 & 15.8 & 101 & 9.1 & 0.001 \\
\hline Bites & 0 & 0 & 82 & 13.3 & 82 & 7.4 & 0.001 \\
\hline Tramadol & 18 & 3.6 & 31 & 5.1 & 49 & 4.4 & 0.093 \\
\hline Alcohols & 1 & 0.2 & 6 & 1 & 7 & 0.6 & 0.006 \\
\hline Hashish & 0 & 0 & 4 & 0.7 & 4 & 0.4 & - \\
\hline Heroin & 0 & 0 & 2 & 0.3 & 2 & 0.2 & - \\
\hline Kerosene & 4 & 0.8 & 32 & 5.3 & 36 & 3.3 & 0.001 \\
\hline Benzene & 2 & 0.4 & 11 & 1.8 & 13 & 1.2 & 0.005 \\
\hline Chlorine gas & 0 & 0 & 24 & 3.9 & 24 & 2.2 & - \\
\hline Carbon monoxide & 0 & 0 & 16 & 2.6 & 16 & 1.4 & - \\
\hline Food poisoning & 0 & 0 & 27 & 4.4 & 27 & 2.4 & - \\
\hline Miscellaneous & 2 & 0.4 & 13 & 2.1 & 15 & 1.4 & 0.010 \\
\hline Unknown & 25 & 5.1 & 30 & 4.9 & 55 & 5 & 0.635 \\
\hline Total & 495 & 100 & 609 & 100 & 1104 & 100 & - \\
\hline
\end{tabular}

Significant $p<0.05, N=$ number

Table (6): Chi square statistical analysis of the studied patients according to types of therapeutic drugs (Number=357) and circumstances of poisoning.

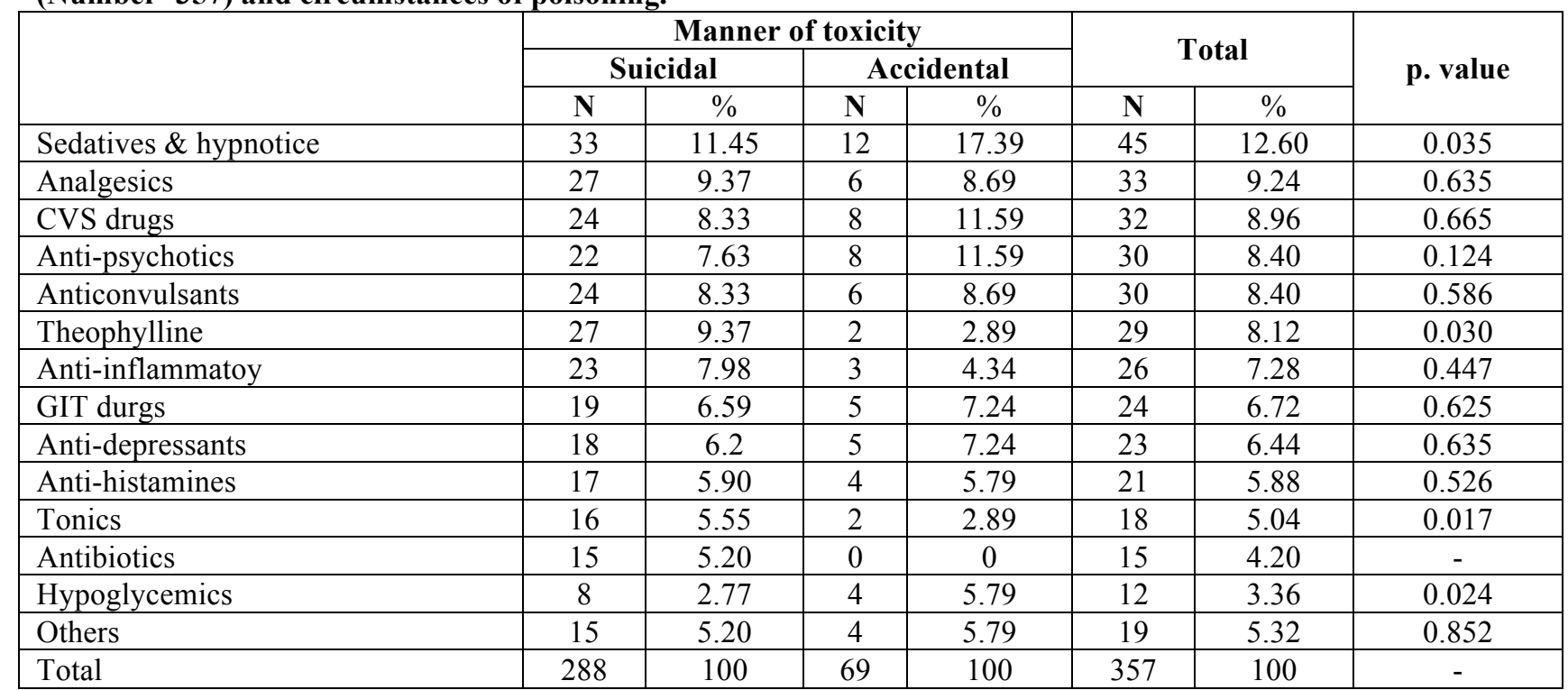

Significant $p<0.05, N=$ number

Table (7): Percentage of studied patients according to different types of pesticides (Number=316).

\begin{tabular}{|l|c|c|}
\hline \multicolumn{1}{|c|}{ Type of pesticide } & $\mathbf{N}$ & $\mathbf{\%}$ \\
\hline Organophosphates & 214 & 67.7 \\
\hline Zinc phosphide & 54 & 17.1 \\
\hline Carbamates & 27 & 8.5 \\
\hline
\end{tabular}




\begin{tabular}{|l|c|c|}
\hline Aluminium phospede & 11 & 3.5 \\
\hline Pyrethroids & 10 & 3.2 \\
\hline Total & 316 & 100 \\
\hline
\end{tabular}

Table (8): Chi square statistical analysis of the studied patients according to types of poisons and gender.

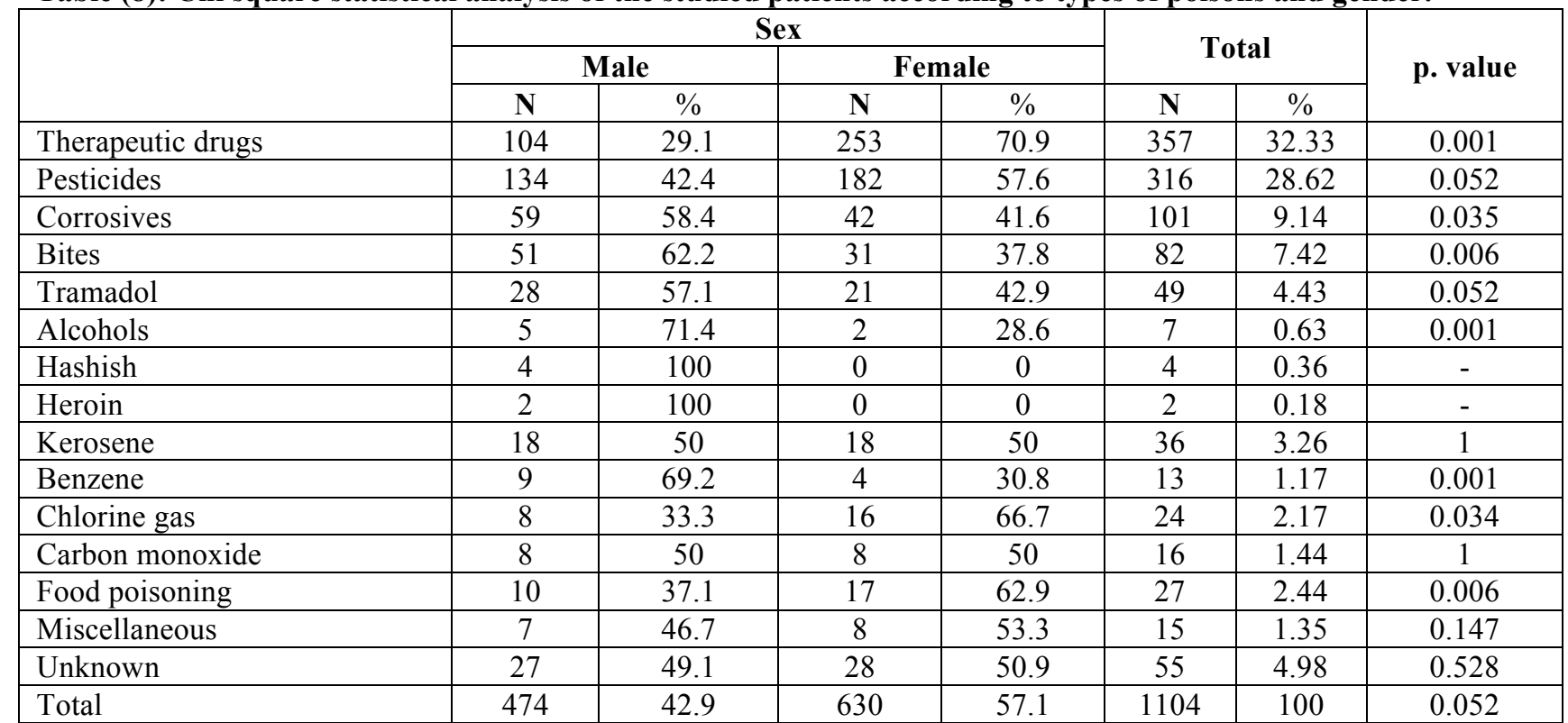

Significant $p<0.05, N=$ number

Table (9): Chi square statistical analysis of the studied patients according to types of poisoning and residence.

\begin{tabular}{|c|c|c|c|c|c|c|c|}
\hline & \multicolumn{4}{|c|}{ Residence } & \multirow{2}{*}{\multicolumn{2}{|c|}{ Total }} & \multirow{3}{*}{ p. value } \\
\hline & \multicolumn{2}{|c|}{ Urban } & \multicolumn{2}{|c|}{ Rural } & & & \\
\hline & $\mathbf{N}$ & $\%$ & $\mathbf{N}$ & $\%$ & $\mathbf{N}$ & $\%$ & \\
\hline Therapeutic drugs & 181 & 50.7 & 176 & 49.3 & 357 & 32.33 & 0.458 \\
\hline Pesticides & 124 & 39.2 & 192 & 60.8 & 316 & 28.62 & 0.036 \\
\hline Corrosives & 36 & 35.6 & 65 & 64.3 & 101 & 9.14 & 0.008 \\
\hline Bites & 35 & 42.7 & 47 & 57.3 & 82 & 7.42 & 0.052 \\
\hline Tramadol & 35 & 71.4 & 14 & 28.6 & 49 & 4.43 & 0.001 \\
\hline Alcohols & 4 & 57.1 & 3 & 42.9 & 7 & 0.63 & 0.052 \\
\hline Hashish & 3 & 75 & 1 & 25 & 4 & 0.36 & 0.003 \\
\hline Heroin & 1 & 50 & 1 & 50 & 2 & 0.18 & 1 \\
\hline Kerosene & 13 & 36.1 & 23 & 63.9 & 36 & 3.26 & 0.019 \\
\hline Benzene & 9 & 69.2 & 4 & 30.8 & 13 & 1.17 & 0.003 \\
\hline Chlorine gas & 13 & 54.2 & 11 & 45.8 & 24 & 2.17 & 0.059 \\
\hline Carbon monoxide & 7 & 43.8 & 9 & 56.3 & 16 & 1.44 & 0.053 \\
\hline Food poisoning & 13 & 48.1 & 14 & 51.9 & 27 & 2.44 & 0.524 \\
\hline Miscellaneous & 5 & 33.3 & 10 & 66.7 & 15 & 1.35 & 0.002 \\
\hline Unknown & 27 & 49.1 & 28 & 50.9 & 55 & 4.98 & 0.458 \\
\hline Total & 506 & 45.8 & 598 & 54.2 & 1104 & 100 & - \\
\hline
\end{tabular}

Significant $p<0.05, N=$ number 


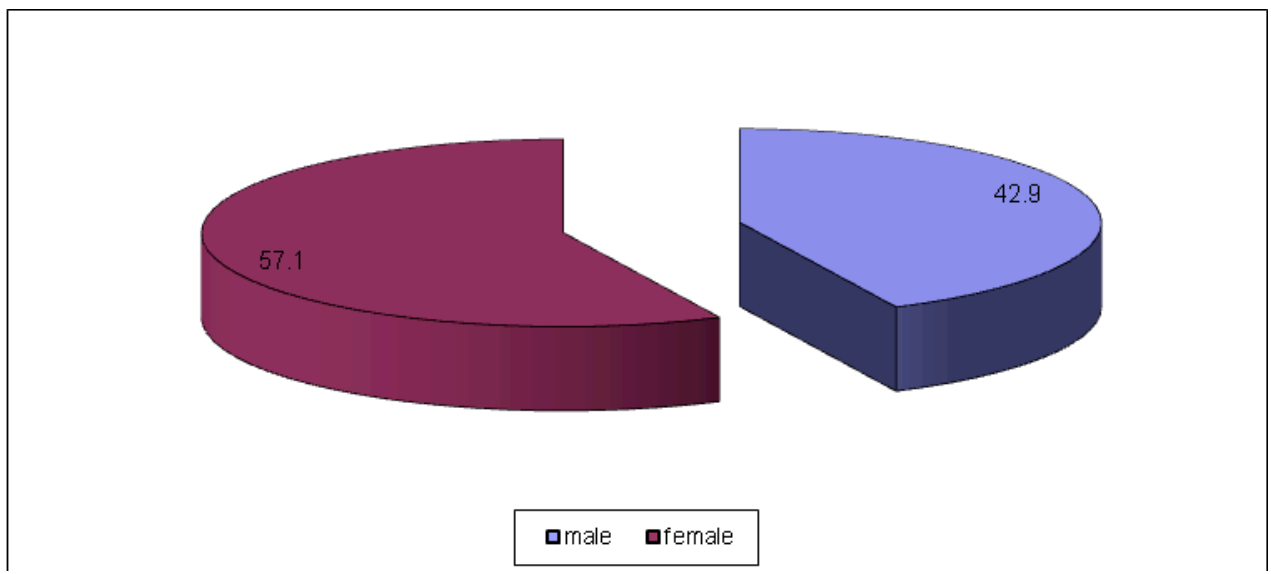

Figure (1): Percentage of studied patients according to gender.

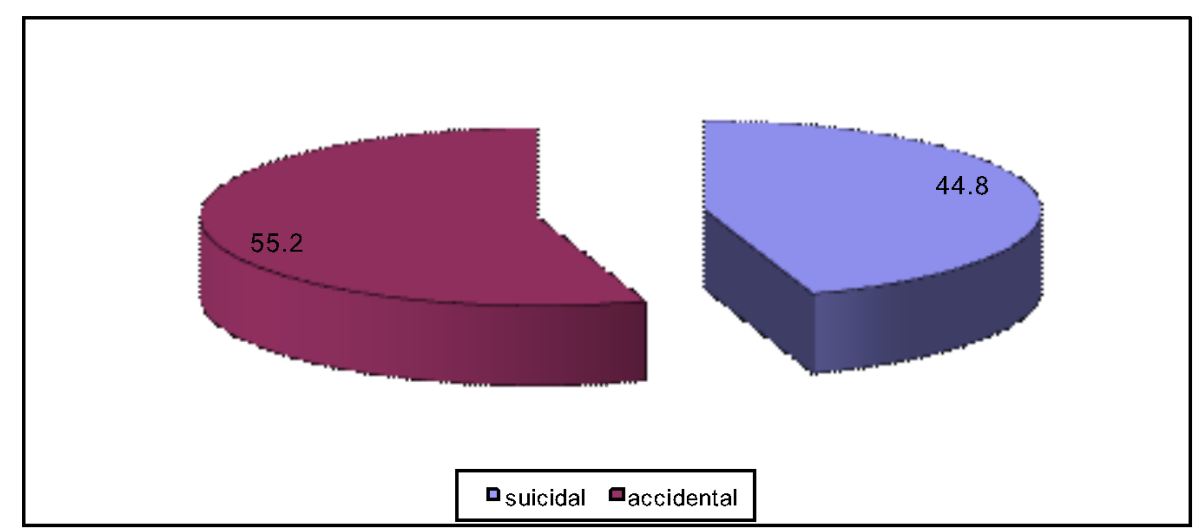

Figure (2): Percentage of studied patients according to circumstances of poisoning.

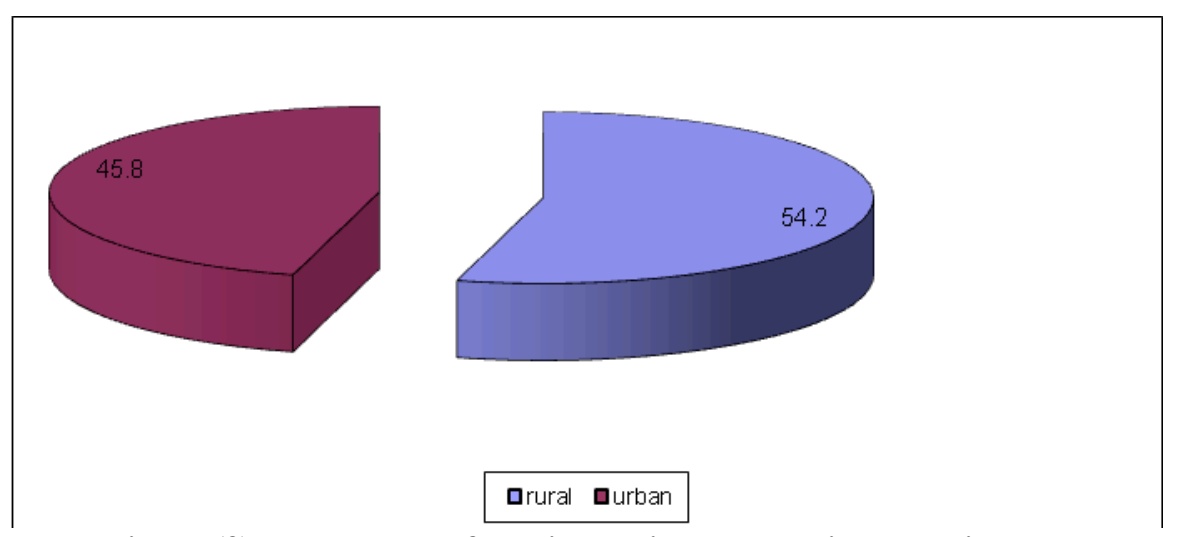

Figure (3): Percentage of studied patients according to residence.

\section{Discussion}

Acute poisoning is a common cause of hospital admissions worldwide. The age of patients included in this study ranged from one year to 75 years. Kanchan et al., (2010) found that the age of the victims ranged from 2 to 82 years with a mean age of 38.4 years.

In this study, acute poisoning primarily involved patients in the age group $1-10$ years $(31.2 \%)$ followed by age group between $11-20$ years (27.4\%), while the least was of the age group more than 60 years $(0.9 \%)$. This was in agreement with Hoffman (2007) who found that the incidence of childhood toxicity ranged from $0.33 \%$ to $6 \%$. Poisoning is most commonly observed at $1-5$ years of age and these children constitute $80 \%$ of all poisoning cases (Jacobsen et al., 1984 and Hovda et al., 2008). This could be explained by the fact that child in this age tries to discover the world around him through his mouth.

Other studies observed that acute poisoning was prevalent among younger adult populations, with less than $3 \%$ of the cases being in people aged 60 years or older in most of previous studies (Crouch et al., 2004; Rogers \&heard, 2007; Cassidy et al.,2008 and Karbakhsh \& Zandi, 2008)

Sharma, (2002) found that involvement of a younger population predominantly during the $3^{\text {rd }}$ and 
$5^{\text {th }}$ decades of life is probably due to the more ambulant nature of younger people.

On the other hand, the results of the current study disagreed with Marahatta et al.,(2009) who found that most poisoning occurred in the age group of above 40 years.

In the current study, $57.1 \%$ were females and $42.9 \%$ were males. This was in agreement with Yang et al., (1996) and Gülğolu \&Kara (2005) who reported that $25.9 \%$ of their study patients were males and $74.1 \%$ of them were females. On contrary, these results disagreed with results obtained by Singh \&Unnikrishnan ((2006) and kanchan et al., (2010) as they found that males were $70.5 \%$ and females were $29.5 \%$ of their study patients. The high predominance of females in our study may be due to higher rate of psychological stress in young women and their tendency to prefer suicide attempt as a way of salvation.

In the current study, suicidal attempts occurred in $44.8 \%$ of patients while accidental poisoning occurred in 55.2\%. Al-Barraq and Farahat, (2011) reported that suicidal cases in a teaching hospital in Riyadh. Saudi Arabia were 25\%.

This was in agreement with Sawalha et al., (2010) who reported unintentional poisoning in $92 \%$ of cases, while the rest were intentional. On the other hand, Akbaba et al.,(2007) found that $87 \%$ of poisoning cases in their study were suicidal attempts while only $13 \%$ were unintentional.

In the current study, accidental poisoning occurred mainly in the age group between 1-10 years among males (58.2\%). Jacobsen et al., (1984) explained that medications given by parents are the main cause of poisoning in the first year of life, while at 2-3 years of age, house cleaning products cause most cases of poisoning and at 3-5 years of age the medications kept in the cupboard or left open are the main causes of poisoning in male children who are naturally in continuous movement.

In the present study, females predominate males in suicidal attempts $(76.2 \%$ and $23.8 \%$ respectively). Among females, suicidal attempts occurred mainly in the age group of 11- 20 years (86.2\%), followed by the age group between 21- 30 years $(69 \%)$, while in males suicidal attempts were mainly among patients between $21-30$ years $(31 \%)$ followed by age group between $11-20$ years $(13.8 \%)$. so, it was observed that suicidal attempts in both males and females occurred mainly between 11- 30 years. This could be attributed to many factors such as poverty, financial problems, unemployment, marital conflicts, breakup in the family support system and stress due to exams among the students.

Findings in this study were in agreement with Bossarte et al.,(2009) and Joe et al.,(2009) who found that females were more significantly likely than males to commit suicidal attempts. On the contrary, it is inconsistent with a previous study of Chinese urban youth which reported absent gender difference (Zhang and Guo, 2003). The significant gender difference could be explained in the light of iron deficiency among women of childbearing age and teenage girls (Li et al., 2007). Decreased brain iron stores may impair the activity of iron-dependent enzymes necessary for synthesis, function, and degradation of serotonin and thus reduced serotonin level which results in impaired inhibition and suicidal or aggressive feelings ( Zimmermann \& Kohrle, 2002 and Beard and Connor, 2003). Varnik et al., (2008) explained this observed sex difference in intention as males use other more violent and lethal suicide methods to a greater extent.

In this study, it was noticed that 2 patients only out of 12 psychiatric patients were accidentally poisoned while the rest (10 patients) attempted suicide. As regard drug abused, 2 out of 23 patients attempted suicide while the rest were accidentally poisoned by an overdose with the drug abused. So, very few number of psychic patients and drug abusers were reported $(1.1 \%$ and $2.1 \%$ respectively). This could be explained by the concept to deny these conditions due to social barriers or fear of legal responsibility.

In the current study, the most common route of poisoning was the oral, it accounted for $82.2 \%$ of patients. This was followed by inhalation $(7.9 \%)$, bites (7.4\%), both inhalation plus dermal (1.1\%), injection $(0.7 \%)$ and lastly dermal $(0.6 \%)$.

These data were in a line with data obtained by Ayoĝlu, et al., (2009). They found that poisons were taken mainly by ingestion (87.8\%), followed by inhalation $(11.9 \%)$, then the combined oral and inhalation $(0.3 \%)$. In contrast Sawalha, et al., (2010) reported that the route of poisoning in their study was mainly through bites and stings (72.3\%) followed by oral route $(23.5 \%)$ then inhalation $(3.4 \%)$. This difference may be explained by the geographic nature of the region, and by the difference in the nature of poisons included in their study and the present study (as the route of intake differs according to the nature of poison).

In the present study, it was noticed that the main route for suicidal attempts was the oral route ( $99.8 \%$ of all suicidal attempts) while one case only was by injection with insulin. On the other hand, accidental poisoning was performed by all the available routes with the commonest is the oral one $(67.9 \%)$ as most cases of accidental were in the age group between $1-10$ years.

Different types of agents were included in this study. The majority was therapeutic drugs (32.3\%) followed by pesticides $(28.6 \%)$ then corrosives $(9.1 \%)$ while bites constituted (7.4\%). Chlorine and carbon monoxide gases were involved in $2.2 \%$ and $1.4 \%$ of cases respectively. As regard recreational substances included in this study, tramadol was found to be the 
commonest of them (4.4\%), then alcohol (0.6\%), hashish $(0.4 \%)$ and lastly heroin $(0.2 \%)$ of all poisoned patients. Food poisoning was $2.4 \%$ of cases. Other agents inluded in this study were kerosene $(3.3 \%)$ and benzene $(1.2 \%)$, other miscellaneous agents constituted $1.4 \%$, while mixture of different unknown agents were used in $5 \%$ of all cases.

Our findings were partially in accordance with Akbaba, et al., (2007) who reported that the frequency of toxins in their study was as follows: therapeutic drugs in $71.1 \%$ of patients, pesticides in $18.9 \%$, caustics in $3.1 \%, \mathrm{CO}$ in $1.8 \%$, foods in $3.7 \%$ and lastly alcohol in $1.45 \%$ of their study patients. Fuller et al., (1989) found that pharmacological agents were the most common cause of poisoning in Western countries. On the other hand, these results disagreed with those of Jaiprakasha, et al., (2011) as they found that poisoning with organophosphorous and organochloride compounds was the commonest (included $60 \%$ of their study cases) followed by aluminum and zinc phosphide (comprised 22\% of cases). Drugs were consumed by the rest of cases (among which phenobarbitone was the commonest).

Therapeutic drugs were the commonest agents used for suicidal attempts $(49.9 \%)$. This could be explained by the fact that drugs could be easily purchased from pharmacies without prescription. Sedatives and hypnotics were the commonest drugs used both suicidally and accidentally while analgesics and theophylline were the second drugs used for suicidal attempts because of their wide use among the Egyptians. Therapeutic drugs were the commonest used in urban areas, this perhaps due to higher socioeconomic level in urban areas, in concert with their prevalence between teenagers and young adults for amusement.

Pesticides in the current study were the commonest agents accidentally used and also they constitute $38.4 \%$ of suicidal attempts. Pesticides were the commonest agents used in rural areas (60.8\%). Florentine and Crane, (2010) stated that the availability of means to commit suicide has a major impact on actual suicides in any region. So, the high incidence of pesticide toxicity was due to their wide use in agriculture and hence their accessibility, low coast and being a household product in both urban and rural areas. In the present study, organophosphates were the commonest, this is because organophosphorous pesticides were commonly used in agriculture over the past decades (Balali-Mood et al.,2012). Females predominated males in using both therapeutic drugs and pesticides; this could be due to over predominance of females in this study.

Corrosives constituted $9.1 \%$ of patients mostly accidental in the range between 1- 10 years. This was in agreement with Pace et al., (2009) who observed that caustic ingestion were commonly in children less than 6years of age. Widespread availability of highly caustic household product, such as window and drain cleaners and diswashing agents has increased the number of accidental caustic injuries in the pediatric population as well as the number of suicide attempts in the adult population (Watson et al., 2005).

As regard bites, the current study revealed that bites constituted $7.4 \%$ of all toxicities and they were totally accidental. Bites were more in males than females $(62.2 \%$ and $37.8 \%$ respectively). It was also observed that bites were more in rural than in urban areas. Most of the snake bite cases were reported in September and October. Most of the victims in our study were bitten outdoors, mostly in the fields during the daytime and on their lower limbs. These bites were mostly due to accidental stamping on a snake while working, an observation that is common to similar studies conducted across India (Sharma, 2002).

Recreational substances included in this study were tramadol, alcohol, hashish and heroin where tramadol was the most prevalent. They were mainly used by drug abusers who got an accidental overdose which brought them to the poison control center. Use of recreational substances was predominant among males and in urban areas. Obviously, tramadol has replaced the other recreational substances in the Egyptian community. It is easily accessible and readily provided at cheap cost despite of it being scheduled. The alleged usages of tramadol had also contributed greatly to its popularity and massive use especially among Egyptian youth as a remedy for premature ejacularity function and for extended orgasm as well as increasing sexual pleasure as promoted through many online drug stores and media (Salem et al., 2008).

There was a highly significance between accidental poisoning with kerosene and its use in suicidal attempts $(p=0.001)$ especially in rural areas where it was still used as a fuel in some types of stoves. Litovitz, (1983) reported that kerosene poisoning sometimes occurs due to negligent repacking of kerosene in improperly labeled containers or bottles.

Benzene was more pronounced among accidentally poisoned patients than suicidal attempts $(\mathrm{p}=0.005)$ with predominance of males over females $(69.2 \%$ and $30.8 \%$ respectively and in urban areas than rural areas $(69.2 \%$ and $30.8 \%$ respectively).potential exposure to benzene in the workplace can be high in certain industries, such as the production of paint and organic chemicals. Environmental exposure can occur from gasoline and cigarette smoke. Indoor exposure could be due to products such as glue, paint, furniture wax, solvents and detergents (Runion \& Scott, 1985; Ayres \& Taylor, 1989 and Wallace, 1990).

Chlorine gas toxicity was also accidental (3.9\% of all accidental cases). Females were more affected than males ( $66.7 \%$ and $33.3 \%$ respectively). Males were mostly below the age of 6 years. One very common method of chlorine exposure is the mixture of 
household bleach with other cleaning agents containing acids or ammonia, as in mixing sodium hypochlorite with hydrochloric acid during cleaning activity This can produce toxic gas and leads to many poison control center visits (Cevik et al., 2009). There is no significance difference between rural and urban areas as regard chlorine toxicity $(\mathrm{p}=0.059)$.

Carbon monoxide (CO) is the commonest cause of inhalatory intoxication worldwide (Duenaslaita et al., 2001; Guratowska et al., 2006). In this study, CO poisoning was totally accidentally $(2.6 \%$ of all accidental cases) due to malfunctions of household devices and/or faulty ventilation and air conditioning systems. No significant difference between urban and rural areas $(\mathrm{p}=0.053)$.

In the current study, number of death cases from poisoning was 5 cases $(0.5 \%)$ who committed suicide with pesticides. Two cases were died with aluminium phosphide, two cases were died from organophosphates and the last case was died from zinc phosphide. This finding was in accordance with Jaiprakasha, et al., (2011). Also, $\mathrm{Hu}$ et al (2010) showed that pesticide poisoning was responsible for the majority of deaths among the elderly poisoned patients. Meanwhile, in a study performed by Shadnia et al., 2007, the mortality rate was $1.3 \%$ (318 patients) and death was mostly occurred by opioids (41.54\%), followed by drugs $(28 \%)$ and pesticides especially organophosphates $(12 \%)$.

Such death rate may be attributed to the substance used and its dose, delay time with increase in the initial peak blood level of poison that may induce irreversible tissue damage (George et al., 2004). In addition, other factors include personal variations, wrong treatment at home or inaccurate diagnosis. Some of the reasons include the dispensing of drugs in envelops instead of child-resistant containers, increased affluence, free medical treatment an easy access to medications without even prescriptions in addition to the careless storage of drugs inside home (Al-Sekait, 1989).

\section{Conclusion}

In Tanta poison control center, the majority of acutely poisoned patients admitted in the year 2012 were in the age group between 1-10 years (31.2\%). Females were $57.1 \%$ while males were $42.9 \%$. Accidental poisoning occurred in $55.2 \%$ while suicidal attempts occurred in $44.8 \%$ of cases. Females $(76.2 \%)$ predominate males $(23.8 \%)$ in suicidal attempts while in accidental poisoning, males $(58.5 \%)$ predominate females (41.5\%). Psychologically disturbed patients were $1.1 \%$ of all acutely poisoned cases while drug abusers were $2.1 \%$. Acute toxicity was more prevalent in rural areas $(54.2 \%)$ than in urban areas $(45.8 \%)$. The oral route was the main route of poison intake in both attempted suicide and accidental poisoning $(82.2 \%)$. Therapeutic drugs were the commonest agents used (32.3\%) followed by pesticides (28.6\%). Among therapeutic drugs, sedatives and hypnotics were the commonest $(12.6 \%)$ while organophosphates were the commonest among pesticides $(67.7 \%)$. Mortality rate was $0.5 \%$.

\section{Recommendations}

The high rate of acute poisoned patients admitted to Tanta poison control center points to the necessity to establish and operate newer centers throughout ElGharbia Governorate and to increase the number of beds and rooms in Tanta poison center. Legislations to ban over the counter selling of medications and to sell potentially dangerous chemicals in waterproof containers must be considered. More attention must be paid especially among families to improve their awareness about safety requirements inside homes. Appropriate prescriptions of drugs especially sedatives hypnotics and analgesics in adults will help to control acute poisoning. Strict control of pesticide accessibility to those with suicidal intent is important in minimizing pesticide poisoning related deaths. Registration of toxicological suicidal attempts as regards to causes, circumstances, substance used, dose, delay time, wrong treatment at home and related socioeconomic conditions will be required to increase toxicological alertness and to protect individuals from taking their own lives. Physicians have the responsibility to provide psychiatric care for people suffering from mental problems or depression. Finally, valuable approaches include patient education and earlier intervention.

\section{References}

Agarwal V and Gupta A (1984): Accidental poisoning in children. Indian Padiatr. 11(9):617-21.

Akbaba M, Nazlican E, Demirhindi H et al., (2007): Etiological and demographical characteristics of acute adult poisoning in Adana, Turkey. Hum Exp Toxicol. 26(5):401-6.

Al-Barraq A and Farahat F (2011): Pattern and determinants of poisoning in a teaching hospital in Riyadh, Saudi Arabia. Saudi Pharmaceutical Journal; 19, 57-63.

Al-Sekait MA (1989): Accidental poisoning of children in Riyadh, Saudi Arabia. Perspect. Public Health; 109 (6), pp. 204-205.

Ayoğlu FN, Ayoğlu H, Kaptan YM et al., (2009): “A Retrospective Analysis of Cases with Acute Poisoning in Zonguldak, Turkey". Türk Anest Der Dergisi; 37(4): 240- 248.

Ayres P H and Taylor WD (1989): Solvents Hayes AH eds. In Principles and Methods of Toxicology, Ed. 2111 Raven Press Ltd. New York .

Balali-Mood M, Balali-Mood K, Moodi M et al., (2012): Health aspects of organophosphorous pesticides in asian countries. Iran $\mathrm{J}$ Public Health. 41(10):1-14. 
Beard JL and Connor JR (2003): Iron status and neutral functioning. Annu Rev Nutr. 23: 41- 58.

Bossarte RM, Swahn MH and Breiding M (2009): Racia, ethnic, and sex differences in the associations between violence and selfreported health among US high school students. J Sch Health. 79: 74- 81.

Buch NA, Ahmed K and Sethi AS (1991): Poisoning in children. Indian Padiatr. 28(5):521-4.

Cassidy N, Lee SKK, Donegan CF et al., (2008): Poisoning in older adults: the experience of the National Poisons Information Centre. Ir Med J;10: 268-70.

Cevik Y, Onay M, Akmaz I et al., (2009): Mass casualties from acute inhalation of chlorine gas. South Med J.102(12):1209-13.

Crouch BI, Caravati EM, itchell A et al., (2004): Poisoning in older adults: a 5-year experience of US poison control centers. Ann Pharmacother; 38:2005-11.

Dueñas-Laita A, Ruiz-Mambrilla M, Gandía F et al., (2001): Epidemiology of acute carbon monoxide poisoning in a Spanish region. $\mathrm{J}$ Toxicol Clin Toxicol 39: 53-57.

Florentine JB and Crane C (2010): suicide prevention by limiting access to methods: A review of theory and practice. Social Science \& Medicine. 70: 1626- 1632.

Fuller GN, Rea AJ, Payne JF et al. (1989): Parasuicides in Central London, 1984-1988. J Roy Soc Med; 82:653-6.

George BK, Pavlos K, George T et al., (2004): "Review of clinical and toxicological features of acute pesticide] poisonings in Crete (Greece) during the period 1991-2001". Med Sci Monit; 10(11): 622- 627.

Gülğolu C and Kara IH (2005): “Acute poisoning cases admitted to a university hospital emergency department in Diyarbakir, Turkey". Hum Exp Toxicol; 24: 49- 54.

Guratowska M, Schmager J, Groszek B et al., (2006): Genotoxic effect of carbon monoxide estimated by the sister-chromatide-exchange test. Przegl Lek 63: 428-432.

Hodgson E (2004): "Introduction to Toxicology". In: A Textbook of Modern Toxicology $3^{\text {rd }}$ ed. Hodgson, E. (Editor). John Wiley \& Sons Inc., Hoboken, New Jersey Pp: 3- 4.

Hoffman RS (2007): Understanding the limitations of retrospective analyses of poison center data. Clin Toxicol (Phila) 45(8):943-5.

Hovda KE, Bjornaas MA, Skog K et al., (2008): Acute poisonings treated in hospitals in Oslo: a oneyear prospective study (I): pattern of poisoning. Clin Toxicol (Phila) 46(1):35-41.

$\mathrm{Hu}$ YH, Chou HL, Lu WH et al., (2010): Features and prognostic factors for elderly with acute poisoning in the emergency department. J Chin Med Assoc; 73:78-87.

Jacobsen D, Frederichsen PS, Knutsen KM et al., (1984): A prospective study of 1212 cases of acute poisoning: general epidemiology. Hum Toxicol. 3(2):93-106.

Jaiprakasha H, Saralaa N, Venkatarathnammab PN et al., (2011): Analysis of different types of poisoning in a tertiary care hospital in rural South India. Food and Chemical Toxicology; Volume 49, Issue 1, Pages 248-250.

Joe S, Baser RS, Neighbors HW et al., (2009): 12month and lifetime prevalence of suicide attempts among black adolescents in the National survey of American Life. J Am Acad Child Adolesc Psychiatry. 48: 271- 82.

Kanchan T, Menezes RG, Ritesh G et al., (2010): Toxicoepidemiology of fatal poisonings in Southern India ?. Journal of Forensic and Legal Medicine; Volume 17, Issue 6, August 2010, Pages 344-347.

Karbakhsh $M$ and Zandi NS (2008): Pattern of poisoning in the elderly: an experience from Tehran. Clin Toxicol (Phila); 46: 211-7.

Li y, Dai Q and Torres E et al. (2007): Gender- specific association between iron status and the history of attempted suicide: Iplications for gender paradox of suicide behaviors. Progress in Neuro- psychopharmacology \& Biological Psychiatry. 31: 149- 1435.

Litovitz T (1983): Hydrocarbon ingestions. Ear, nose \& throat J 62: 142-7.

Marahatta SB, Singh J, Shrestha R et al., (2009): "Poisoning cases attending emergency department in Dhulikhel Hospital- Kathmandu University Teaching Hospital". KUMJ; 7(26):152- 156 .

Mutlu M, Cansu A, Karakas T et al., (2010): Pattern of pediatric poisoning in the east Karadeniz region between 2002-2006: increased suicide poisoning. Hum Exp Toxicol. 29(2):131.

Pace F, Antinori S and Repici A (2009): What is new in esophageal injury (infection, drug-induced, caustic, stricture, perforation)? Current Opinion in Gastroenterology. 25:372-379.

Pillay VV (2004): Text book of forensic medicine and toxicology, 14th edition. Paras Publication: New York; 350.

Rogers JJ and Heard K (2007): Does age matter? Comparing case fatality rate for selected poisoning reported to US poison centers. Clin Toxicol (Phila); 45:705-8.

Runion H E and Scott LM (1985): Benzene exposure in the United States 1978-1983: an overview. Am. J. Ind. Med., 7: 385-393.

Sahin S, Carman KB and Dinleyici EC (2011): Acute poisoning in children; data of a pediatric emergency unit. Iran J Pediatr. 21(4):479-84. 
Salem EA, Wilson SK, Bissada NK et al., (2008): Tramadol HCL has promise in on-demand use to treat premature ejaculation. J Sex Med 5(1):188-93.

Sawalha AF, Sweileh WM, Tufaha MT et al., (2010): "Analysis of the Pattern of Acute Poisoning in Patients Admitted to a Governmental Hospital in Palestine". Basic Clin Pharmacol Toxicol; 107: 914- 918.

Shadnia S, Esmaily H, Sasanian G et al., (2007): Pattern of acute poisoning in Tehran-Iran in 2003. Human \& Experimental Toxicology; 26: 753-756.

Sharma BD (2002): Indian Poisonous Snakes: An Ecological and Clinical Study. New Delhi: Anmol Publications Pvt. Ltd.

Singh B and Unnikrishnan B (2006): A profile of acute poisoning at Mangalore (South India). Journal of Clinical Forensic Medicine; Volume 13, Issue 3, April, Pp 112-116.

Varnik A, Kolves K, van der Feltz-Cornelis CM et al., (2008): Suicide methods in Europe: a genderspecific analysis of countries participating in the "European Alliance Against Depression". J Epidemiol Community Health. 62(6):54551.

Wallace L (1990): Major sources of exposure to benzene and other volatile organic chemicals. Risk Anal., 10: 59.

Watson WA, Litovitz TL, Klein-Schwartz et al., (2004): "2003 Annual Report of the American Association of Poison Control Centers; Toxic
Exposure Surveillance System”. Am J Emerg Med; 22: 335- 404.

Watson WA, Litovitz TL, Rodgers GC Jr et al., (2005): 2004 Annual report of American association of poison control centers toxic exposure surveillance system. Am J Emerg Med. 23:589-666.

Yang CC (2010): Acute Poisoning in the Elderly: An Increasingly Recognized But Still Overlooked Problem. J Chin Med Assoc; April • Vol 73 • No 4.

Yang CC, Wu JF, Ong HC et al. (1996): Taiwan National Poison Center: epidemiologic data 1985-1993. J Toxicol Clin Toxicol; 34:65163.

Zhang ZQ and Guo LT (2003): A cross- sectional study on suicide attempts in urban middle school students in Chengdu [in Chinese]. Zhonghua Liu Xing Bing Xue Za Zhi. 24: 189-91.

Zimmermann MB and Kohrle J (2002): The impact of iron and selenium deficiencies on iodine and thyroid metabolism: biochemistry and relevance to public health. Thyroid. 12:867878 .

\title{
الملخص العربي
}

\section{نمط التسمم الحاد بين المرضى الذين أدخلوا مركز علاج التسمم بطنطا خلال عام 2012}

\author{
منى محمد ابو النور 1
}

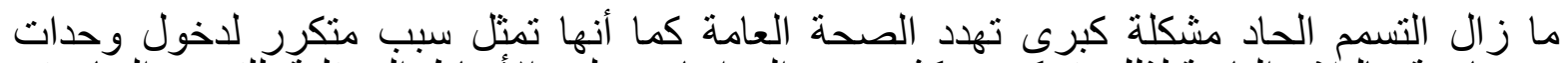

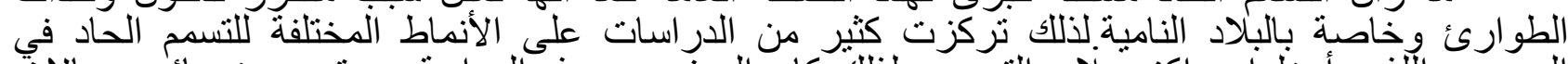

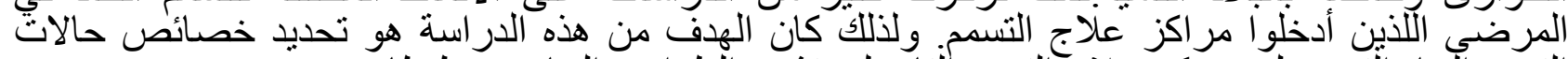

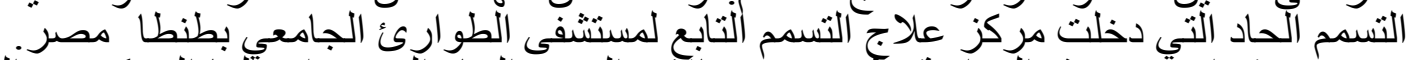

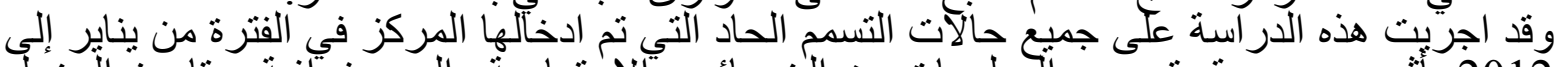

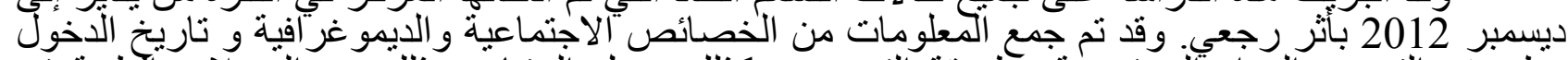

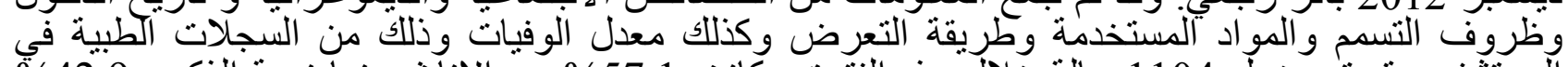

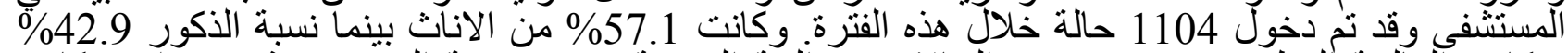

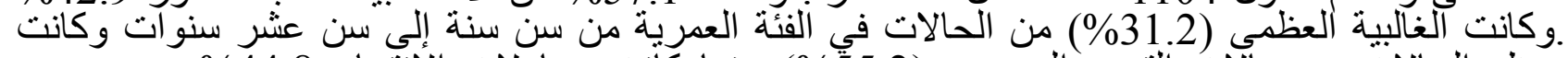

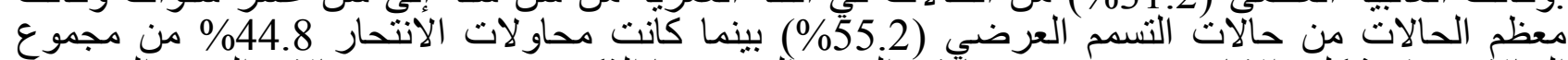

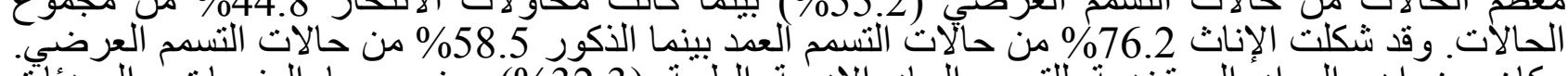

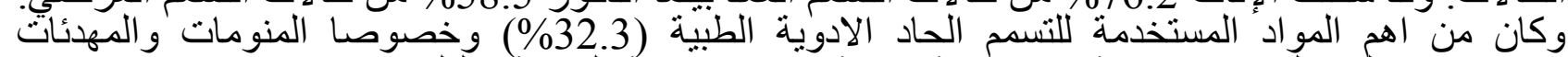

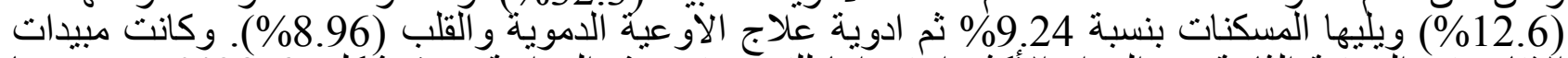

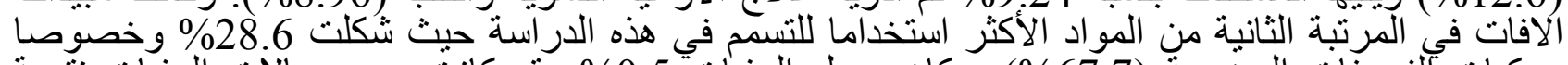

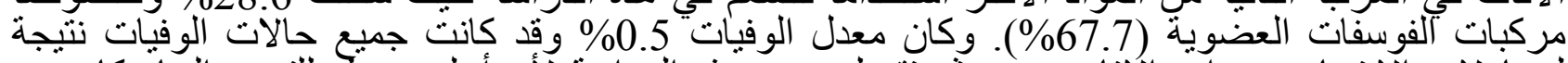

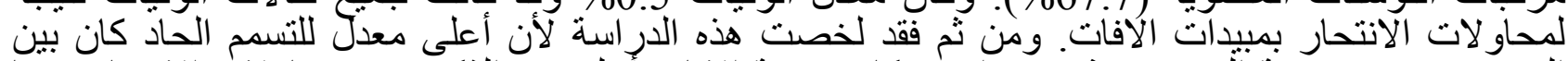

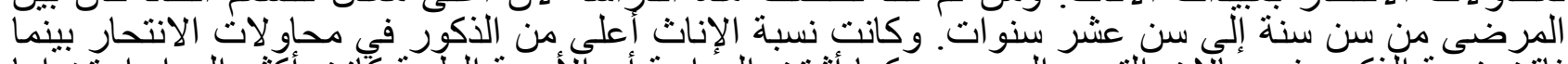

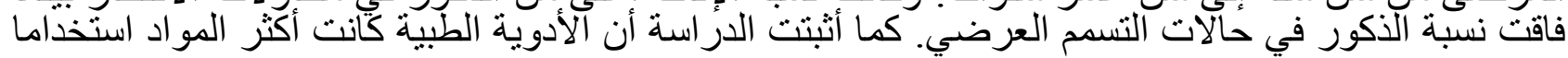


تلتها مبيدات الآفات.وتوصي الدر اسة بأن توضع خطة لتحديد تداول المواد الأكثر استخداما في حالات التسمم

1 قسم الطب الثرعي والسموم كلية الطب جامعة طنطا 